\title{
Energy expenditure, physical activity and basal metabolic rate of elderly subjects
}

\author{
BY DAPHNE L. E. PANNEMANS AND KLAAS R. WESTERTERP \\ Department of Human Biology, University of Limburg, PO Box 616, 6200 MD Maastricht, \\ The Netherlands
}

(Received 28 April 1993 - Revised 22 August 1994 - Accepted 23 August 1994)

\begin{abstract}
Energy expenditure, and therefore energy requirement, generally decreases with advancing age because of a decrease in basal metabolic rate (BMR) and physical activity. The aim of the present study was to measure total energy expenditure (EE) and activity level in a group of healthy elderly (sixteen men aged 71.3 (SD 4.9) years; ten women aged 67.6 (SD 4.1) years) and young adults (nineteen men aged 30.4 (SD 5.0) years; ten women aged 27.2 (SD 3.9) years) by using the doubly-labelled water method in combination with measurements of BMR. Age-related differences in body composition and their relationship to BMR and activity level were studied. EE was lower in elderly compared with young adults, partly due to a significantly lower BMR. The lower BMR was not fully explained by the lower fat-free mass (FFM) in the elderly. Energy expended (MJ/d) on activity was higher for the younger subjects although there was no significant difference in the physical activity index (PAI $=E E / B M R)$ between the two age groups. The effect of physical activity level is twofold: first it has a positive effect on the BMR, and second it has a positive effect on the FFM. Both effects involve an increase in the total EE with an increased level of physical activity. At energy balance this will lead to increased energy and nutrient intake, making especially the elderly less vulnerable to inadequate energy and nutrient intake.
\end{abstract}

Energy expenditure: Physical activity: Basal metabolic rate: Elderly

Several factors contribute to the amount of energy required by an individual: basal metabolic rate (BMR), physical activity and to a lesser extent diet-induced thermogenesis (DIT). The basal metabolic needs are the energy requirements at complete rest and these are closely related to body composition. The energy required above the basal needs is determined by the level of physical activity, for example the energy expended during work and leisure. The DIT is the rise in metabolic rate as a consequence of eating and accounts for about $10 \%$ of the energy intake.

In general, energy expenditure (EE), and therefore energy requirement, decreases with increasing age, first because of a decrease in BMR as shown in many studies (Keys et al. 1973; Tzankoff \& Norris, 1977; Calloway \& Zanni, 1980). BMR decreases as a consequence of decreasing fat-free mass (FFM) with ageing (Forbes \& Reina, 1970). However, it is not clear whether the loss of FFM fully explains the lower BMR in the elderly since other physiological factors probably also contribute to the decreased BMR (Fukagawa et al. 1990; Poehlman et al. 1991; Vaughan et al. 1991). Second, EE decreases because the elderly tend to be less active (McGandy et al. 1966; Dallosso et al. 1988). However, these observations are limited to measures obtained from self-recorded physical activity diaries or motion sensors. Only a few studies have reported total EE in the elderly measured with doubly-labelled water (Goran \& Poehlman, 1992; Roberts et al. 1992; Pannemans \& Westerterp, 1993; Reilly et al. 1993). Using this technique, EE can be measured under free-living conditions and, by simultaneously measuring BMR, it is 
possible to assess EE for daily activity by expressing physical activity in multiples of BMR or by expressing the energy expended on physical activity (plus thermogenesis) as EE minus BMR. In this way the EE can be measured more precisely.

Summarizing the literature, it can be concluded that it remains unclear whether the decline in EE, the changes in body composition and the decrease in BMR are immutable consequences of the ageing process or whether they are subject to the influence of changes in lifestyle (e.g. physical activity) and/or other physiological changes. The aim of the present study was to measure total EE and activity level in a group of healthy elderly and young men and women using the doubly-labelled water method in combination with measurements of BMR. By measuring body composition with deuterium dilution, agerelated differences in body composition and their relationship to BMR and physical activity level were studied.

\section{SUBJECTS AND METHODS}

\section{Subjects}

The subjects were twenty-nine young adults and twenty-eight elderly adults (as described by Pannemans \& Westerterp, 1993). Elderly and young adults were studied exactly 1 year after each other, to avoid weather and seasonal influences on e.g. physical activity, body weight and composition of the nutrients used for the diets. Subjects were recruited by advertisements in the local media. Elderly subjects were also recruited through contacts with alliances for the elderly. One elderly man and one elderly woman were excluded because of missing values. Mean age, height, weight and body mass index (BMI) are presented in Table 1 . All subjects were certified to be in good health by a staff physician and gave informed consent to participate in the study after the procedures were explained to them. The protocol was approved by the university ethics committee.

\section{Protocol}

EE, energy balance, BMR and body composition were measured during a nutrition intervention study as previously reported for the elderly subjects (Pannemans \& Westerterp, 1993; Pannemans et al. 1995). Briefly, subjects were given two isoenergetic diets for 3 weeks each in a crossover design with a 'wash-out' period of at least 3 weeks. Diets contained 12 and 42 , and 21 and $33 \%$ of total energy intake from protein and fat respectively. Subjects received both diets in different orders, which were chosen at random for each volunteer. Usual daily energy intake was measured before the start of the experiment with a $4 \mathrm{~d}$ dietary record (eleven elderly subjects) or with a dietary questionnaire (fifteen elderly subjects and twenty-nine young adults). During the experiment subjects were fed according to their estimated energy intake. During the experiment all meals, consisting of breakfast, lunch, dinner, beverages and drinks, were served daily at home, and subjects were not allowed to eat or drink anything else except for water, tea and coffee. The first week was an adjustment period in which energy intake could be adjusted if necessary. Fig. 1 is a schematic representation of the experimental design.

\section{Measurement of energy expenditure}

EE was measured over 2 weeks in the first experimental period (Fig. 1) with doubly-labelled water. Subjects drank a weighed amount of ${ }^{18} \mathrm{O}$ and ${ }^{2} \mathrm{H}$. The dosage calculation was based on body mass in order to create a ${ }^{2} \mathrm{H}$ excess of $150 \mathrm{ppm}$ and an ${ }^{18} \mathrm{O}$ excess of $300 \mathrm{ppm}$. The isotope was administered in the evening between 22.00 and 23.00 hours, just before the subjects went to sleep, after collecting a background urine sample. Further urine samples were collected 1,8 and $15 \mathrm{~d}$ after drinking the isotope. Isotopes were measured in urine using an isotope-ratio mass spectrometer (Aqua Sira; VG Isogas Ltd, Middlewich, 
Table 1. Characteristics of the subjects

(Mean values and standard deviations)

\begin{tabular}{|c|c|c|c|c|c|c|c|c|c|}
\hline \multirow[b]{2}{*}{ Subjects } & \multirow[b]{2}{*}{$n$} & \multicolumn{2}{|c|}{$\begin{array}{c}\text { Age } \\
\text { (years) }\end{array}$} & \multicolumn{2}{|c|}{$\begin{array}{l}\text { Height } \\
\text { (m) }\end{array}$} & \multicolumn{2}{|c|}{$\begin{array}{l}\text { Weight } \\
(\mathrm{kg})\end{array}$} & \multicolumn{2}{|c|}{$\begin{array}{l}\text { Body mass index } \\
\qquad\left(\mathrm{kg} / \mathrm{m}^{2}\right)\end{array}$} \\
\hline & & Mean & SD & Mean & SD & Mean & SD & Mean & SD \\
\hline Elderly men & 16 & $71 \cdot 3$ & $4 \cdot 9$ & $1 \cdot 72^{* * *}$ & 0.09 & $74 \cdot 0$ & 12.6 & $25 \cdot 0^{*}$ & $3 \cdot 3$ \\
\hline Young men & 19 & 30.4 & $5 \cdot 0$ & $1 \cdot 81$ & 0.05 & $76 \cdot 3$ & 8.6 & $23 \cdot 2$ & $2 \cdot 0$ \\
\hline Elderly women & 10 & $67 \cdot 6$ & $4 \cdot 1$ & $1 \cdot 60^{*}$ & 0.08 & $65 \cdot 4$ & 5.9 & $25 \cdot 6 * *$ & $2 \cdot 6$ \\
\hline Young women & 10 & $27 \cdot 2$ & 3.9 & 1.68 & 0.06 & $60 \cdot 8$ & $7 \cdot 5$ & $21 \cdot 5$ & $2 \cdot 0$ \\
\hline
\end{tabular}

Mean values were significantly different from those of the corresponding young group: ${ }^{*} P<0.05,{ }^{* *} P<0.01$, $* * * P<0.001$ (unpaired $t$ test).

\begin{tabular}{lll|} 
& $\left.\right|^{1}$ & $\left.\right|^{2}$ \\
Eneeks & & $x \times x$ \\
Basal metabolic rate & $x$ & $x$ \\
Body composition & $x$ & $x$ \\
Energy expenditure & $x \times x \times x \times x \times x \times x x x$
\end{tabular}

Fig. 1. Energy expenditure, energy balance, basal metabolic rate and body composition were measured during a nutrition intervention study. Subjects were given two isoenergetic diets for 3 weeks each in a crossover design with a 'wash-out' period of at least 3 weeks. Diets contained 12 and 42, and 21 and $33 \%$ of total energy intake from protein and fat respectively. Subjects received both diets in different orders, which were chosen at random for each volunteer.

Cheshire) and $\mathrm{CO}_{2}$ production was calculated from isotope ratios in baseline, $1 \mathrm{~d}, 8 \mathrm{~d}$, and $15 \mathrm{~d}$ samples using the equation of Schoeller as described by Westerterp \& Saris (1991). $\mathrm{CO}_{2}$ production was converted to EE using a respiratory quotient of 0.85 according to the food quotient of the diet.

\section{Energy balance}

Gross energy intake (GEI) was calculated by measuring the energy content of the food given during the experimental period with bomb calorimetry (Janke \& Kunkel, IKA Kalorimeter C-400; adiabatisch, Staufen im Breisgau, Germany). Subjects collected faeces and urine for 3 and $2 \mathrm{~d}$ respectively at the end of each experimental period. After the volumes of urine and faeces were measured, about $1.5 \mathrm{~g}$ homogenized faeces and $25 \mathrm{ml}$ urine (in portions of $5 \mathrm{ml}$ ) were freeze dried. Afterwards the energy content was measured. By subtracting the energy content of faeces and urine from GEI, metabolizable energy (ME) was calculated. Energy balance during the first experimental period was calculated by subtracting ME from EE.

\section{Measurement of basal metabolic rate}

A computerized, open-circuit, ventilated-hood system was used to measure BMR. BMR can be calculated by determining the amount of air flowing through the hood and by measuring the $\mathrm{O}_{2}$ and $\mathrm{CO}_{2}$ concentrations in the incoming and outcoming air. Subjects came to the laboratory in the early morning after an overnight fast of at least $10 \mathrm{~h}$. Subjects were asked to travel by car, bus or train in order to reduce physical activity. BMR was measured for 
at least $20 \mathrm{~min}$ under thermoneutral temperature conditions, after a period of at least $20 \mathrm{~min}$ bed-rest. The subjects were instructed to relax and avoid sleeping during measurements. BMR was measured on four occasions (Fig. 1) for most subjects.

\section{Body weight and body composition}

Subjects' body weight (BW) and body composition were measured on the same days as BMR was measured (Fig. 1). Subjects were weighed in underwear in the morning, after voiding and before eating or drinking, on a balance accurate to $0 \cdot 1 \mathrm{~kg}$. Body composition was measured on the same days with deuterium dilution. Subjects drank a ${ }^{2} \mathrm{H}_{2} \mathrm{O}$ dilution in the evening after emptying the bladder (baseline sample). The second voiding in the next morning was the second sample. Deuterium was measured in the urine samples using an isotope-ratio mass spectrometer as described above. Total body water (TBW) was calculated as the measured deuterium dilution space divided by 1.04 (Schoeller, 1992). FFM was calculated as $\mathrm{TBW} / 0 \cdot 73$.

\section{Statistics}

Values are expressed as means and SD. Data previously obtained in elderly subjects in an identical experimental protocol are used for comparative purposes. Differences between measurements and groups were analysed using Student's paired and unpaired $t$ tests as appropriate. Regression analysis was used to assess associations between measured variables. Analysis of co-variance using FFM as the co-variate was used to adjust for differences in body composition when comparing BMR values. Analysis of variance for repeated measures was used to identify the effect of the diet on change in body weight, BMR and ME. Since the diet had no effect on these variables, both diet periods are treated as identical.

\section{RESULTS}

Energy balance

The results of the energy balance measurements are given in Table 2. GEI, ME and EE were significantly higher for the young adults. As reported before for the elderly (Pannemans \& Westerterp, 1993), ME intake was significantly lower than EE $(P<0.001$ for elderly and $P<0.0001$ for young adults). ME represented 92.0 (SD 10.3) $\%$ of EE in the elderly and 87.2 (SD 14.5) \% in the young adults. Energy balance, defined as ME-EE, was -0.83 (SD 1.00$) \mathrm{MJ} / \mathrm{d}$ and -1.62 (SD 1.78 ) $\mathrm{MJ} / \mathrm{d}$ for the elderly and the young adults respectively. The energy balance was negative in both groups but did not differ significantly between the two age groups. For both groups there was a significant relationship between energy balance and the weight change over $14 \mathrm{~d}$ in the first experimental period (Fig. 2). The regression lines between these two variables do not differ significantly for elderly and young subjects indicating that age has no effect on this relationship.

\section{Measurement of body weight and body composition}

BW and body composition were measured four times in fifty-three subjects. Two elderly women were measured twice, being involved only in the first experimental period. For this reason, in the first experimental period comparisons were made between twenty-six elderly and twenty-nine young subjects while during the second period comparisons were made between twenty-four elderly and twenty-nine young subjects. Table 3 shows the results during both experimental periods. There were no significant differences in BW between young and elderly subjects. However, body composition did differ since elderly subjects had a significantly higher fat mass (FM) and a significantly lower FFM compared with the young adults (FM: $P<0.01$; FFM: $P<0.05$ ). BW decreased significantly during both 
Table 2. Energy balance $(M J / d)$ in elderly and young adults as calculated during the first experimental period $\uparrow$

(Mean values and standard deviations)

\begin{tabular}{|c|c|c|c|c|}
\hline & \multicolumn{2}{|c|}{$\begin{array}{l}\text { Elderly adults } \\
\qquad(n 26)\end{array}$} & \multicolumn{2}{|c|}{$\begin{array}{l}\text { Young adults } \\
\text { (n 29) }\end{array}$} \\
\hline & Mean & SD & Mean & SD \\
\hline Gross energy intake & $9 \cdot 72^{* *}$ & $1 \cdot 35$ & $11 \cdot 30$ & 1.94 \\
\hline Energy in faeces & 0.57 & $0 \cdot 11$ & 0.55 & $0 \cdot 19$ \\
\hline Energy in urine & $0 \cdot 39$ & $0 \cdot 16$ & $0 \cdot 48$ & $0 \cdot 10$ \\
\hline Metabolizable energy & $8 \cdot 77^{* *}$ & $1 \cdot 31$ & $10 \cdot 27$ & 1.85 \\
\hline Energy expenditure & $9 \cdot 60^{* * * *}$ & 1.56 & $11 \cdot 89$ & 1.84 \\
\hline
\end{tabular}

Mean values were significantly different from those for young adults: ** $P<0.01, * * * *<<0.0001$ (unpaired $t$ test).

$\uparrow$ For details of protocol, see Fig. 1.

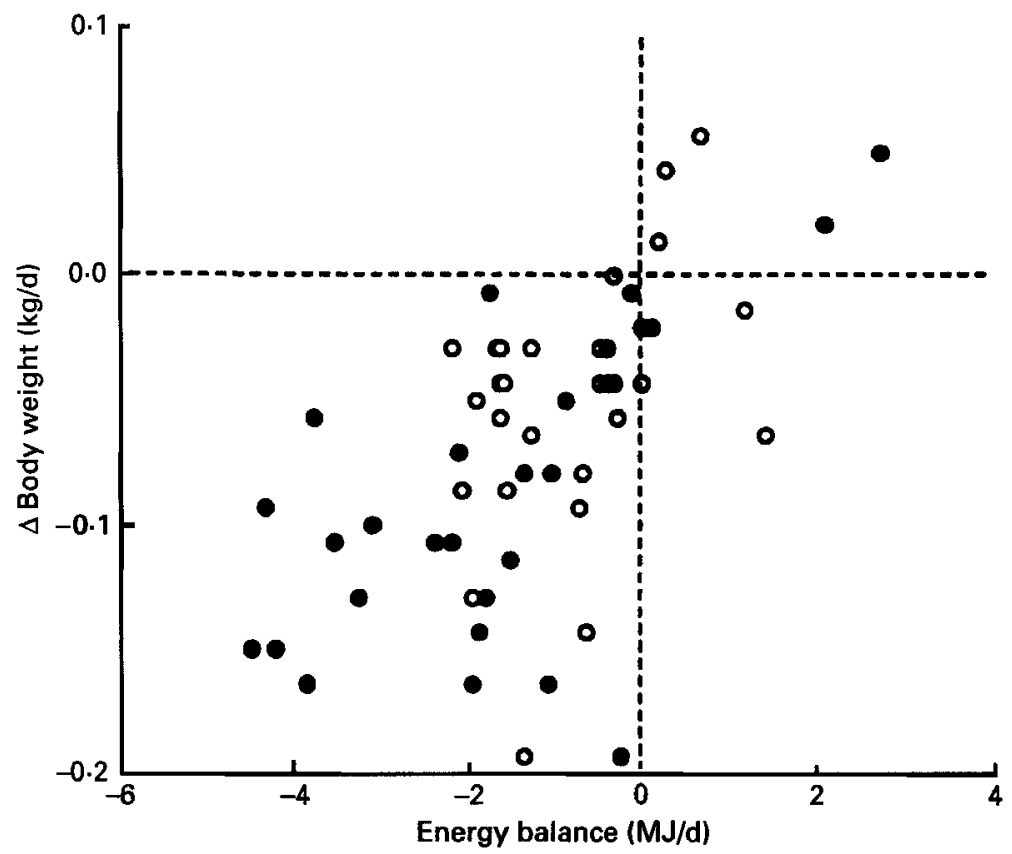

Fig. 2. Change in body weight $(\triangle \mathrm{BW})$ plotted as a function of the energy balance (metabolizable energy (ME) intake minus energy expenditure (EE)) in a group of twenty-nine young adults $(O)$ and also in a group of twentysix elderly subjects $(O)$ as described previously (Pannemans \& Westerterp, 1993). Calculated linear regression lines were: young adults: $\triangle \mathrm{BW}=0.02(\mathrm{ME}-\mathrm{EE})-0.05(r 0.646 ; P<0.001)$; elderly subjects: $\Delta \mathrm{BW}=$ $0.02(\mathrm{ME}-\mathrm{EE})-0.03(r 0.448 ; P<0.05)$; young and elderly subjects : $\Delta \mathrm{BW}=0.02(\mathrm{ME}-\mathrm{EE})-0.04(r 0.601 ; P<$ $0.0001)$.

experimental periods in both age groups $(P<0.0001$ for both age groups during the first experimental period; $P<0.001$ for elderly and $P<0.0001$ for young subjects during the second experimental period). As shown in Table 3, measured weight loss was due to a decrease in FM. FM decreased significantly during both experimental periods. 
Table 3. Body weight $(\mathrm{kg})$ and body composition $(\mathrm{kg})$ of elderly and young adults during both experimental periods $;$

(Mean values and standard deviations)

\begin{tabular}{|c|c|c|c|c|c|}
\hline & \multirow[b]{2}{*}{ Measurement } & \multicolumn{2}{|c|}{ Elderly adults } & \multicolumn{2}{|c|}{ Young adults } \\
\hline & & Mean & SD & Mean & SD \\
\hline \multirow[t]{4}{*}{ Body weight } & 1 & $70 \cdot 69+1+1+$ & $11 \cdot 23$ & $70.99+1+1+$ & $11 \cdot 01$ \\
\hline & 2 & $69 \cdot 98$ & $10 \cdot 84$ & $69 \cdot 78$ & $10 \cdot 69$ \\
\hline & 3 & $69 \cdot 90 \dagger+\dagger$ & $11 \cdot 11$ & $70.61 \mathrm{t \dagger \dagger \dagger}$ & $10 \cdot 79$ \\
\hline & 4 & $69 \cdot 34$ & 10.83 & $69 \cdot 48$ & $10 \cdot 61$ \\
\hline \multirow[t]{4}{*}{ Fat-free mass } & 1 & $48 \cdot 47^{* *}$ & 8.99 & $55 \cdot 71$ & $9 \cdot 20$ \\
\hline & 2 & $49 \cdot 3^{*}$ & $9 \cdot 09$ & $55 \cdot 64$ & $9 \cdot 02$ \\
\hline & 3 & $49 \cdot 62^{*}$ & $9 \cdot 27$ & $55 \cdot 58$ & $9 \cdot 11$ \\
\hline & 4 & $49 \cdot 78^{*}$ & 8.95 & 55.48 & $9 \cdot 12$ \\
\hline \multirow[t]{4}{*}{ Fat mass } & 1 & $21 \cdot 81 * * * *+\dagger+\dagger$ & $6 \cdot 15$ & $15 \cdot 26+t+t \dagger$ & 5.56 \\
\hline & 2 & $20-85^{* * * *}$ & 6.01 & $14 \cdot 15$ & 4.99 \\
\hline & 3 & $20-28^{* *+} \dagger$ & $6 \cdot 10$ & $15 \cdot 44+4+\dagger$ & $5 \cdot 17$ \\
\hline & 4 & $19 \cdot 56^{* * *}$ & $6 \cdot 34$ & 13.99 & $5 \cdot 24$ \\
\hline
\end{tabular}

Mean values were significantly different from those for young adults: * $P<0.05,{ }^{* *} P<0.01,{ }^{* * *} P<0.001$, **** $P<0.0001$ (unpaired $t$ test).

Mean values for the first and third measurements were significantly different from those for the second and fourth measurements respectively: $\uparrow P<0.05,+\uparrow+P<0.001,+\uparrow \uparrow \dagger P<0.0001$.

$\ddagger$ For details of protocol, see Fig. 1 .

$\S$ Body weight, fat-free mass and fat mass were measured twice ( 1 and 2$)$ in the first experimental period (elderly $n 26$, young $n 29$ ) and twice (3 and 4) during the second period (elderly $n 24$, young $n 29$ ).

\section{Measurement of basal metabolic rate}

BMR was measured at least twice in all subjects ( $n$ 55). Fifty-three subjects were measured at least three times and fifty subjects were measured four times. Within-subject variation (over two, three or four measurements) was 4.6 (SD 2.2) \% for elderly and $5 \cdot 2$ (SD 1.9) \% for young subjects, justifying taking the mean of the available measurements (Weststrate, 1993). Mean BMR values for the elderly (6.22 (SD 1.01) MJ/d) were significantly lower than values obtained for the younger subjects (7.14 (SD 0.95) MJ/d;P<0.001). These differences were analysed in relation to differences in body composition. Adjusted BMR values, according to the age-specific relationships between BMR and FFM for elderly and young subjects, were calculated (Ravussin \& Bogardus, 1989; Weinsier et al. 1992). Adjusted BMR values were significantly lower for the elderly (6.38 (SD 0.56) and 7.43 (SD 0.40) MJ/d for the elderly and young subjects respectively, $P<0.0001$ ). Regression lines between FFM and BMR for young and elderly subjects were compared as shown in Fig. 3. For both age groups there was a significant relationship between both variables $(P<0.0001)$. As tested with analysis of covariance, the $y$-intercepts, but not the slopes, between young and elderly subjects were significantly different $(P<0.05)$.

\section{Measurement of the physical activity level}

Physical activity level was calculated as the physical activity index (PAI), given as EE divided by BMR (calculated in this way PAI includes a DIT term). Means and ranges of measured PAI are given in Table 4. Young men had a significantly higher mean PAI compared with elderly men. No other differences between sexes or age groups were seen although there was a tendency for young subjects to have a higher PAI compared with the 


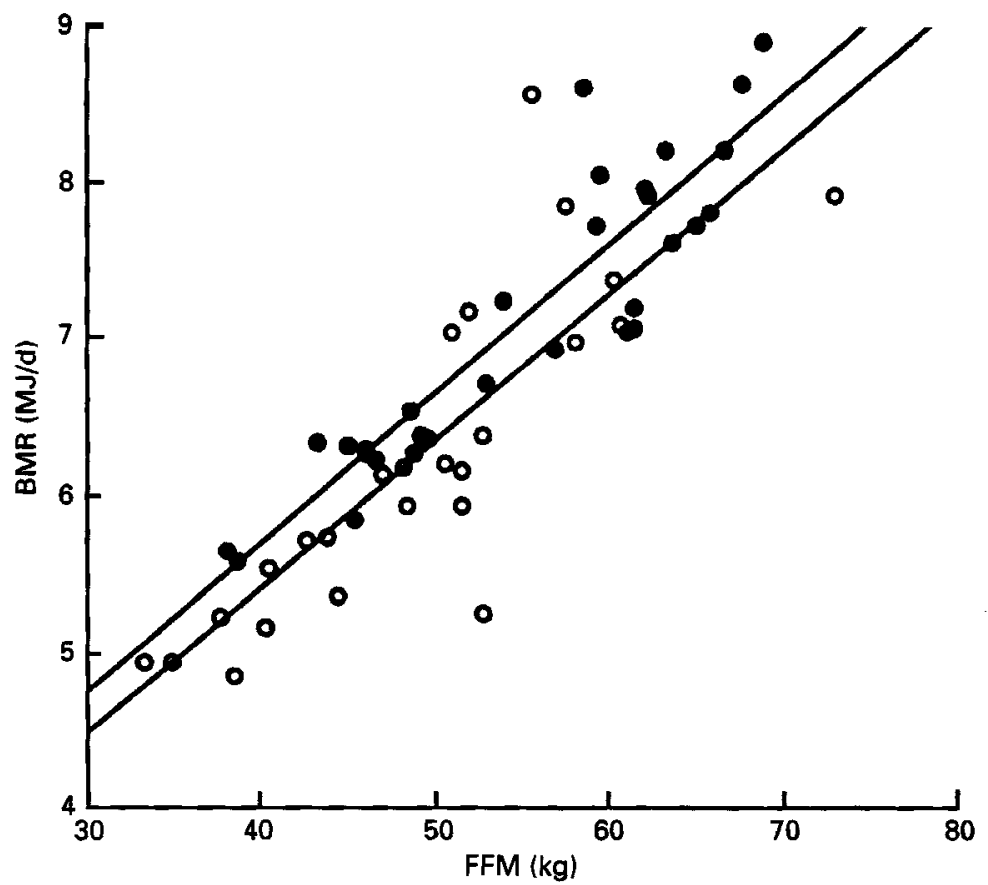

Fig. 3. Basal metabolic rate (BMR) plotted as a function of the fat-free mass (FFM) in a group of twenty-nine young adults $(O)$ and also in a group of twenty-six elderly subjects $(O)$. Calculated linear regression lines were: young adults: $\mathrm{BMR}=0.09 \mathrm{FFM}+1.85(r 0.910 ; P<0.0001)$; elderly subjects: BMR $=0.09 \mathrm{FFM}+1.64(r 0.834 ;$ $P<0.0001$ ). The intercepts of the linear regression lines were significantly different (analysis of co-variance, $P<0.05)$.

Table 4. Physical activity levels of elderly and young adults expressed as physical activity index $(P A I)$

(Mean values and standard deviations)

\begin{tabular}{|c|c|c|c|c|}
\hline & \multirow[b]{2}{*}{ Subjects } & \multicolumn{3}{|c|}{ PAI +} \\
\hline & & Mean & SD & Range \\
\hline & Elderly ( $n$ 26) & 1.58 & 0.21 & $1 \cdot 27-2 \cdot 05$ \\
\hline & Elderly men ( $n$ 16) & 1.52 & 0.20 & $1 \cdot 27-2 \cdot 05$ \\
\hline & Elderly women ( $n$ 10) & 1.66 & $0 \cdot 20$ & $1 \cdot 34-2 \cdot 00$ \\
\hline & Young adults $(n 29)$ & 1.66 & $0 \cdot 16$ & $1 \cdot 32-2 \cdot 06$ \\
\hline & Young men $(n 19)$ & 1.66 & 0.15 & $1 \cdot 32-1 \cdot 86$ \\
\hline & Young women $(n 10)$ & $1 \cdot 67$ & $0 \cdot 20$ & $1 \cdot 42-2 \cdot 06$ \\
\hline
\end{tabular}

* Mean value was significantly different from that for young men, $P<0.05$ (unpaired $t$ test).

$\dagger$ Calculated as energy expenditure divided by basal metabolic rate.

elderly $(P=0.081)$. There was no significant relationship between PAI and body composition (FFM, FM, percentage FM and BMI).

Multiple regression analysis revealed that the physical activity level (as given by EE/BMR) and the FFM of the subjects contributed significantly to the BMR. FFM and PAI explained respectively 80 and $86 \%$ of the variance in BMR in elderly and young 
subjects. In the elderly, PAI explained $10 \%$ extra of the variance in BMR; this was only $3 \%$ (though significant) in the young adults. The absolute amount of energy expended on physical activity (EE-BMR) was positively $(P<0.01)$ correlated with the fat-free mass index $\left(F F M I=F F M /\right.$ height $\left.^{2}\right)$. In this way corrections were made for differences in height, in analogy with the BMI (Westerterp et al. 1992).

\section{DISCUSSION}

Despite the baseline period, in which corrections of intake could be made when subjects lost weight or complained of hunger or satiation, subjects were in negative energy balance. The negative energy balance is corroborated by the significant correlation between change in body weight $(\Delta \mathrm{BW})$ and energy balance for both age groups, and is also reflected in a significant decrease in FM. Roberts et al. (1991) did not find a significant relationship between $\triangle \mathrm{BW}$ and energy balance; this can be explained by the fact that in the present study energy balance was more negative and energy balance was measured over longer periods. Before discussing the other results it has to be noticed that, because of the randomized crossover design of the study, the negative energy balance had no effect on the conclusions from the results presented. Furthermore, multiple regression analysis using the energy balance (ME-EE) data as one of the variables (besides e.g. FFM and PAI) revealed that there was no significant contribution of energy balance to the measured variables (e.g. BMR).

The effect of age on energy metabolism was investigated by measuring total EE, BMR and the energy needs for physical activity in healthy young and elderly subjects. EE and therefore energy intake was significantly lower for the elderly. EE is mainly determined by BMR and by the energy expended in physical exercise.

BMR was measured at least twice in all subjects. The mean coefficient of variation was about $5 \%$ for both age groups, a value comparable with other studies (Fredrix et al. 1990; Poehlman et al. 1992). Absolute BMR values (MJ/d) were lower in the elderly relative to the young adults $( \pm 13 \%)$. In the past, numerous studies have reported lower BMR values in elderly compared with young subjects. In a longitudinal study reported by Keys $e t$ al. (1973) BMR declined $2 \%$ per decade of age. In cross-sectional studies (Tzankoff \& Norris, 1977; Calloway \& Zanni, 1980), elderly subjects had a significantly higher FM and a significantly lower FFM compared with the young adults but BMR values were also lower in the elderly when differences in FFM were taken into account using analysis of covariance. These findings support those of Fukagawa et al. (1990), Poehlman et al. (1991) and Vaughan et al. (1991) who also found that differences in FFM cannot account fully for the lower BMR in older subjects.

Elderly subjects tended, although not significantly, to be less active in comparison with younger subjects when physical activity was expressed in multiples of $\operatorname{BMR}(P=0.081)$. The current recommendations as given by the Food and Agriculture Organization/World Health Organization/United Nations University (FAO/WHO/UNU) (1985) for energy requirements in adults with different activity levels are also expressed as multiples of BMR. These recommendations have been questioned recently by Roberts et al. (1991, 1992). It was suggested that the current recommended energy intake for young and elderly subjects may significantly underestimate usual energy requirements since the activity levels of the subjects, who were classified on the basis of a questionnaire as 'sedentary', were significantly higher compared with the FAO/WHO/UNU (1985) recommendations (1.75 compared with 1.50 as recommended for the elderly and 1.98 compared with 1.55 or 1.67 for young adults). However, when comparing the PAI values of the present study (1.58 (SD 0.21) for elderly subjects as reported earlier (Pannemans \& Westerterp, 1993) and 1.67 
(SD 0.17) for the young adults) with those recommended by the FAO/WHO/UNO (1985), no significant differences were seen. Our results are in accordance with results of the study of Goran \& Poehlman (1992) who reported mean activity levels of 1.51 for elderly men and women. Compared with other studies (Schulz et al. 1989; Livingstone et al. 1990) in young adults our PAI values are slightly lower ( 1.67 compared with 1.92 and 1.82 respectively). This is probably due to the fact that in the study of Schulz et al. (1989) the subjects were a small group of young students who, in general, have a higher physical activity level. Furthermore, the time of year can influence the physical activity level of the subjects. We measured EE in February and March, probably explaining the lower PAI levels in our group. Recently Reilly et al. (1993) reported a mean PAI of 1.80 for elderly women but this rather high activity level was in accordance with the activity questionnaire score, indicating that the subjects involved in the study were more physically active than the mean of a large sample of women of similar age in another study (Dallosso et al. 1988). Reilly et al. (1993) pointed out the fact that the interpretation of the PAI values requires some caution: PAI may be unjustly raised in elderly subjects since their BMR is reduced relative to that of young adults (because of a decrease in FFM); at the same level of physical activity this would raise the PAI with advancing age. When physical activity (plus thermogenesis) is expressed as EE minus BMR the elderly subjects expended significantly less energy on activity in comparison with the younger ones $(3.46$ (SD 1.18$) \mathrm{MJ} / \mathrm{d}$ for the elderly and 4.73 (SD 1.25$) \mathrm{MJ} / \mathrm{d}$ for the young adults; $P=0.0003$ ).

As mentioned earlier, the age-related decrease in FFM could not fully explain the decrease in BMR. Therefore the effect of the level of physical activity on the decrease in BMR with age was investigated. Recently Poehlman et al. (1992) examined the effects of aerobic capacity, body composition and thyroid hormones on the age-related decline in $\mathrm{BMR}$ and concluded that maintenance of FFM and $\mathrm{VO}_{2}$ max by regular physical activity may attenuate the age-related decline in BMR in healthy subjects. In a previous study from the same group (Poehlman et al. 1991) it was also concluded that regular physical exercise, as assessed from an exercise history questionnaire, may contribute to a higher BMR. In contrast to the studies of Poehlman et al. $(1991,1992)$, in the present study the physical activity level was actually measured and confirmed earlier findings. Physical activity (as given by EE/BMR) of the subjects contributed significantly to the BMR. FFM and PAI explained respectively 80 and $86 \%$ of the variance in BMR in elderly and young subjects. Only speculations can be made on what accounts for the 14 to $20 \%$ of variance in BMR which is not explained by the activity index or the FFM. The circulating levels of thyroid hormones, catecholamines, insulin or growth hormone might account for the unexplained variance in BMR. Furthermore, processes like protein turnover can also affect the BMR.

In addition the effect of physical activity on body composition was studied. The absolute amount of energy expended on physical activity (EE-BMR) was positively $(P<0.01)$ correlated with the fat-free mass index $\left(F F M I=F F M /\right.$ height $\left.{ }^{2}\right)$. In this way corrections were made for differences in height, in analogy with the BMI (Westerterp et al. 1992). These results indicate that physical activity has a positive effect on the FFM. It is speculated that the level of physical activity may attenuate the decrease in FFM with age.

In conclusion, EE was lower in elderly compared with young adults due to a decreasing BMR. The decrease in BMR was not fully explained by the decrease in FFM in the elderly. The absolute amount of energy expended on activity was higher for the younger subjects although there was no significant difference in PAI between the two age groups. The physical activity level (measured as PAI) together with the FFM explained respectively 80 and $86 \%$ of the variance in BMR in elderly and young subjects. The absolute amount of energy expended on activity was positively correlated with the FFMI, indicating a positive effect of physical activity on FFM. So, the effect of physical activity is twofold: first it has 
an effect on the BMR, and second it has a positive effect on the FFM. Both effects involve an increase in the total EE with an increased level of physical activity. At energy balance this will lead to an increased energy and nutrient intake, making especially the elderly less vulnerable for inadequate energy and nutrient intake.

\section{REFERENCES}

Calloway, D. H. \& Zanni, E. (1980). Energy requirements and energy expenditure of elderly men. American Journal of Clinical Nutrition 33, 2088-2092.

Dallosso, H. M., Morgan, K., Bassey, E. J., Ebrahim, S. B. J. \& Fentem, P. H. (1988), Levels of customary physical activity among the old and the very old living at home. Journal of Epidemiology and Community Health 42, 121-127.

Food and Agriculture Organization/World Health Organization/United Nations University (1985). Energy and Protein Requirements. Technical Report Series no. 724. Geneva: WHO.

Forbes, G. B. \& Reina, J. C. (1970). Adult lean body mass declines with age: some longitudinal observations. Metabolism 19, 653-663.

Fredrix, E. W. H. M., Soeters, P. B., Deerenberg, I. M., Kester, A. D. M., von Meyenfeldt, M. F. \& Saris, W. H. M. (1990). Resting and sleeping energy expenditure in the elderly. European Journal of Clinical Nutrition 44, 741-747.

Fukagawa, N. K., Bandini, L. G. \& Young, J. B. (1990). Effect of age on body composition and resting metabolic rate. American Journal of Physiology 259, E233-E238.

Goran, M. I. \& Poehlman, E. T. (1992). Total energy expenditure and energy requirements in healthy elderly persons. Metabolism 41, 744-753.

Keys, A., Taylor, H. L. \& Grande, F. (1973). Basal metabolism and age of adult man. Metabolism 22, 579-587.

Livingstone, M. B. E., Prentice, A. M., Strain, J. J., Coward, W. A., Black, A. E., Barker, M. E., McKenna, P. G. \& Whitehead, R. G. (1990). Accuracy of weighed dietary records in studies of diet and health. British Medical Journal 300, 708-712.

McGandy, R. B., Barrows, C. H., Spanias, A., Meredith, A., Stone, J. L. \& Norris, A. H. (1966). Nutrient intakes and energy expenditure in men of different ages. Journal of Gerontology 21, 581-587.

Pannemans, D. L. E., Halliday, D. \& Westerterp, K. R. (1995). Whole body protein turnover in elderly men and women: responses to two levels of protein intake. American Journal of Clinical Nutrition 61, 33-38.

Pannemans, D. L. E. \& Westerterp, K. R. (1993). Estimation of energy intake to feed subjects at energy balance as verified with doubly labelled water: a study in the elderly. European Journal of Clinical Nutrition 47, 490-496.

Poehlman, E. T., Berke, E. M., Gardner, A. W., Katzman-Rooks, S. M. \& Goran, M. I. (1992). Influence of aerobic capacity, body composition, and thyroid hormones on the age-related decline in resting metabolic rate. Metabolism 41, 915-921.

Poehlman, E. T., McAuliffe, T. L., van Houten, D. R. \& Danforth, E. (1990). Influence of age and endurance training on metabolic rate and hormones in healthy men. American Journal of Physiology 259, E66-E72.

Poehlman, E. T., Melby, C. L. \& Badylak, S. F. (1991). Relation of age and physical exercise status on metabolic rate in younger and older healthy men. Journal of Gerontology 46, B54-B58.

Ravussin, E. \& Bogardus, C. (1989). Relationship of genetics, age and physical fitness to daily energy expenditure and fuel utilization. American Journal of Clinical Nutrition 49, 968-975.

Reilly, J. J., Lord, A., Bunker, V. W., Prentice, A. M., Coward, W. A., Thomas, A. J. \& Briggs, R. S. (1993). Energy balance in healthy elderly women. British Journal of Nutrition 69, 21-27.

Roberts, S. B., Heyman, M. B., Evans, W. J., Fuss, P., Tsay, R. \& Young, V. R. (1991). Dietary energy requirements of young adult men, determined by using the doubly labeled water method. American Journal of Clinical Nutrition 54, 499-505.

Roberts, S. B., Young, V. R., Fuss, P., Heyman, M. B., Fiatrone, M., Dallal, G. E., Cortiella, J. \& Evans, W. J. (1992). What are the dietary energy needs of elderly adults? International Journal of Obesity 16, 969-976.

Schoeller, D. A. (1992). Isotope dilution methods. In Obesity, pp. 80-88 [P. Bjöntorp and B. N. Brodoff, editors]. Philadelphia: J. B. Lippencott Company.

Schulz, S., Westerterp, K. R. \& Brück, K. (1989). Comparison of energy expenditure by the doubly labeled water technique with energy intake, heart rate, and activity recording in man. American Journal of Clinical Nutrition 49, 1146-1154.

Tzankoff, S. P. \& Norris, A. H. (1977). Effect of muscle mass decrease on age-related BMR changes. Journal of Applied Physiology 43, 1001-1006.

Vaughan, L., Zurlo, F. \& Ravussin, E. (1991). Aging and energy expenditure. American Journal of Clinical Nutrition 53, 821-825.

Weinsier, R. L., Schutz, Y. \& Bracco, D. (1992). Reexamination of the relationship of resting metabolic rate to fat-free mass and to the metabolically active components of fat-free mass in humans. American Journal of Clinical Nutrition 55, 790-794. 
Westerterp, K. R., Meijer, G. A. L., Kester, A. D. M., Wouters, L. \& ten Hoor, F. (1992). Fat-free mass as a function of fat mass and habitual activity level. International Journal of Sports Medicine 13, 163-166.

Westerterp, K. R. \& Saris, W. H. M. (1991). Limits of energy turnover in relation to physical performance, achievement of energy balance on a daily basis. Journal of Sports Sciences 9, 1-15.

Weststrate, J. A. (1993). Resting metabolic rate and diet induced thermogenesis: a methodological reappraisal. American Journal of Clinical Nutrition 58, 592-601. 